Article

\title{
Enabling School Bureaucracy, Psychological Empowerment, and Teacher Burnout: A Mediation Analysis
}

\author{
Kwok Kuen Tsang *, Guangqiang Wang * and Hui Bai
}

College of Education Administration, Faculty of Education, Beijing Normal University, Beijing 100875, China; 202021010158@mail.bnu.edu.cn

* Correspondence: kktsang@bnu.edu.cn (K.K.T.); 202021010165@mail.bnu.edu.cn (G.W.)

check for updates

Citation: Tsang, K.K.; Wang, G.; Bai, H. Enabling School Bureaucracy, Psychological Empowerment, and Teacher Burnout: A Mediation Analysis. Sustainability 2022, 14, 2047. https://doi.org/10.3390/su14042047

Academic Editors:

Arantzazu Rodríguez-Fernández, Arantza Fernández-Zabala and Eider Goñi-Palacios

Received: 5 January 2022

Accepted: 7 February 2022

Published: 11 February 2022

Publisher's Note: MDPI stays neutral with regard to jurisdictional claims in published maps and institutional affiliations.

Copyright: (C) 2022 by the authors. Licensee MDPI, Basel, Switzerland. This article is an open access article distributed under the terms and conditions of the Creative Commons Attribution (CC BY) license (https:// creativecommons.org/licenses/by/ $4.0 /)$.

\begin{abstract}
Teacher burnout is a psychological phenomenon affecting teachers' effectiveness and wellbeing across the globe. Thus, education researchers have investigated its antecedents to identify approaches to alleviate teacher burnout. However, many of the existing studies tend to underline the effects of psychological factors but overlook the effects of structural factors on teacher burnout. Thus, the aim of this study is to fill the research gap by investigating how teacher burnout is affected by enabling school bureaucracy as a structural factor and psychological empowerment as a psychological factor based on empowerment theory. By using the self-administrated questionnaire survey, the study investigated 322 primary and secondary schoolteachers from China. It finds that structural empowerment and psychological empowerment are negatively associated with teacher burnout. Moreover, the relationship between structural empowerment and teacher burnout was mediated by psychological empowerment, especially its dimensions of meaning and competence.
\end{abstract}

Keywords: enabling school bureaucracy; structural empowerment; psychological empowerment; teacher burnout

\section{Introduction}

Teaching is one of the most stressful occupations in the world [1] because it requires teachers to deal with challenging students and parents $[2,3]$ and handle heavy instructional, administrative, and pastoral workloads every day $[4,5]$. Therefore, compared with many other occupations, teachers are more prone to burnout [6,7]. According to Maslach et al. [8], burnout is a psychological syndrome consisting of emotional exhaustion (the depletion of emotional sources), depersonalization (the feelings of detachment from and cynicism towards a job), and reduced personal accomplishment (a decline in the feelings of competence and efficacy at work). The syndrome is reported to have negative associations with teachers' job dissatisfaction, commitment, work performance, and wellbeing [9-12]. Thus, conventional education studies have investigated the antecedents of teacher burnout from a psychological perspective to identify effective interventions to alleviate teacher burnout [13]. Although their studies have identified that teacher burnout is associated with a variety of psychological or individual factors, such as personality [14], self-efficacy belief [15], coping strategies [16], and emotional intelligence [17], most of them tend to neglect the structural effects of schools on teacher burnout. Pietarinen et al. [18] suggest that burnout is a sociocontextual construct, implying that burnout is not purely affected by psychological factors but also structural factors. Therefore, Leiter and Maslach [19] call for the extension of study on burnout from the psychological perspective to the organizational perspective that is concerned with structural influences on burnout. To respond to this call, studies have paid attention to structural factors of organizations and identified the structural factors such as organizational support [20], organizational culture [21], organizational justice [22], value dissonance or conflict [23], and occupational demands and resources [24] as the predictors of burnout. Accordingly, if a strategy cannot confront issues on the psychological factors and structural factors of schools, it may not be able to 
alleviate teacher burnout effectively [25]. In theory, enabling school bureaucracy should be a factor alleviating teacher burnout because it can empower teachers in workplace [26,27]. Nevertheless, education researchers have paid little attention to the effects of enabling school bureaucracy on teacher burnout. Thus, as informed by empowerment theory, the present study aims to advance our understandings of teacher burnout by investigating the relationship of teacher burnout to enabling school bureaucracy as a structural factor of schools and psychological empowerment as a psychological factor.

\section{Empowerment Theory}

Empowerment theory generally concerns the processes and outcomes of enabling people to control their work and take action to improve their situations by increasing their power at the psychological and/or structural level [28,29]. According to Rappaport [30], empowerment may occur at multiple levels because it is a mechanism by which individuals and organizations gain mastery over their affairs. Thus, researchers have developed different approaches to investigate and promote the process of empowerment [31]. In general, these approaches can be categorized into organizational and motivational perspectives [32]. From the organizational perspective, empowerment is a process determined by organizational structure that enables people to reach their work goals through access to opportunities, information, support, and resources [33]. Thus, this perspective pays attention to the structural aspect of empowerment and seeks to promote enabling organizational structure to achieve structural empowerment [34]. On the other hand, the motivational perspective suggests that empowerment reflects an intrinsic incentive or a need for selfdetermination or self-efficacy [35]. To highlight the psychological aspect, empowerment refers to psychological empowerment and defines psychological empowerment as the cognitive state of mind about the self-capability to influence one's work and social environment [29,32]. In particular, Spreitzer [36] conceptualizes psychological empowerment as a motivational construct manifested in four cognitions, including meaning (the value of a work goal or purpose), competence (the belief in the self-capability to perform activities with skill), self-determination (the sense of having choice in initiating and regulating behaviors), and impact (the degree to which a person can influence outcomes at work). Therefore, this perspective has been investigated for means to psychologically empower people by effectively enhancing their sense of meaning, competence, self-determination, and impact [37].

Although the structural and motivational perspectives emphasize different dimensions of empowerment, it does not mean they are incompatible, because of their shared theoretical ground; empowerment, whether it is structural or psychological, can lead to better work performance and wellbeing of people, since it enables them to exercise control over their work and identify the meaningful connections between themselves and their work [38-40]. Moreover, it is suggested that structural and psychological empowerment may be interdependent [41]. According to Spreitzer [42], psychological empowerment may be affected by organizational structure; if an organization's structure is enabling, it is easier for its people to feel psychologically empowered, and vice versa. On the other hand, Weidenstedt [41] notes that structural empowerment may not be successful; however, enabling the organizational structure is necessary if people do not feel they are being empowered. Thus, empowerment theory draws researchers' attention to the relationship between organizational structure and individual psychology and its effects on people's work and wellbeing.

\section{Theoretical Framework}

\subsection{Enabling Bureaucracy and Teacher Burnout}

According to empowerment theory, an enabling school structure is a crucial factor to alleviate teacher burnout because it implies structural empowerment. In modern societies, schools generally have trappings of the organizational structure of bureaucracy that emphasize the formalization of rules and procedures and the centralization of power and 
authority at the top of the hierarchy [43]. School bureaucratization has become more apparent since the 1990s, when the management logics of accountability and performativity were introduced into education systems [44]. From the literature, it is noted that bureaucracy may be coercive and hindering because it tends to force people to submit themselves to it and do their work without an understanding of and/or control over the purposes that it defines [45]. Thus, school bureaucracy may structurally disempower teachers, leading them to be more prone to burnout $[46,47]$.

Nevertheless, Hoy and Sweetland [27] find that school bureaucracy may not necessarily be coercive and hindering. They find that school bureaucracy ranges along a continuum from hindering to enabling. According to their studies, enabling school bureaucracy consists of enabling centralization, i.e., a hierarchy of authority facilitating collaboration across authority boundaries rather than retaining distinctive roles, and enabling formalization, i.e., a system of rules and regulations facilitating problem-solving rather than publishing failure [27]. If a school develops an enabling bureaucratic structure, it tends to value "shared authority within established roles, two-way communication, seeing problems as opportunities, respecting differences, engendering trust, learning from mistakes, and welcoming the unexpected" [48]. The literature has illustrated that this kind of school structure is inclined to structurally empower teachers to do their work in line with their interests and values and to identify the meaningful connections between themselves and their work, resulting in job satisfaction, commitment, enthusiasm, and lesser degrees of powerlessness and demoralization [27,49]. Since the literature consistently shows that burnout is negatively associated with job satisfaction, commitment, and enthusiasm [12,50], but positively associated with the sense of powerlessness and demoralization [51,52], the present study proposes the following hypothesis:

Hypothesis 1 (H1). Enabling school bureaucracy is negatively associated with teacher burnout.

\subsection{Psychological Empowerment and Teacher Burnout}

As mentioned, psychological empowerment is one's cognitive state, manifested in meaning, competence, self-determination, and impact [36]. Thus, once a person is psychologically empowered, he or she should have a positive sense of work meaning, self-efficacy, and self-concept leading to satisfaction, motivation, and innovation [53]. Moreover, studies demonstrate that psychological empowerment may generate a sense of accomplishment because psychological empowerment may stimulate people's potential and personal values and motivate them to actively do their work [35]. In this sense, psychological empowerment may alleviate burnout. For example, Boudrias et al. [54] show that psychological empowerment significantly reduced job burnout among Canadian health care workers. Ghaniyoun et al. [55] indicate a negative association between psychological empowerment and job burnout among operational staff of emergency centers in Tehran. Moreover, Zhu [56] identifies a significant negative relationship between teachers' psychological empowerment and burnout, and, in particular, he shows that meaning, self-determination, and competence negatively and significantly predict teacher burnout. Similarly, in their recent study, Tsang et al. [57] find that the three dimensions of psychological empowerment may alleviate teacher burnout in China. Accordingly, Hypothesis 2 is formulated as follows:

\section{Hypothesis 2 (H2). Psychological empowerment is negatively correlated with teacher burnout.}

\subsection{Mediation Effect of Psychological Empowerment}

The literature suggests that structural empowerment and psychological empowerment should be positively correlated [40]. Further analyses on their relationship suggest that structural empowerment may be a necessary antecedent of psychological empowerment [58]. As Laschinger et al.'s [38] study shows, nurses' psychological empowerment may be affected by the structural empowerment of their work setting. In other words, structural empowerment may not only directly affect people's work and wellbeing, but 
also indirectly influence them via psychological empowerment. For instance, Knol and Linge [59] show that psychological empowerment is a mediator between the structural empowerment and innovative behavior of nurses. In addition, Paryadharshany and Sujatha [39] identify the mediation effect of psychological empowerment on the relationship between structural empowerment and job satisfaction. Moreover, Meng et al. [60] demonstrate that the impacts of structural empowerment on job burnout may be mediated by psychological empowerment. These existing studies imply that enabling school bureaucracy can alleviate teacher burnout not only because it can structurally empower teachers but also because it may lead them to feel psychologically empowered. Accordingly, the present study infers that psychological empowerment may function as a mediator between enabling school bureaucracy and teacher burnout.

Hypothesis 3 (H3). Psychological empowerment plays a mediating role in the relationship between enabling school bureaucracy and teacher burnout.

The hypothesized relationships among enabling school bureaucracy, psychological empowerment, and teacher burnout are illustrated in Figure 1.

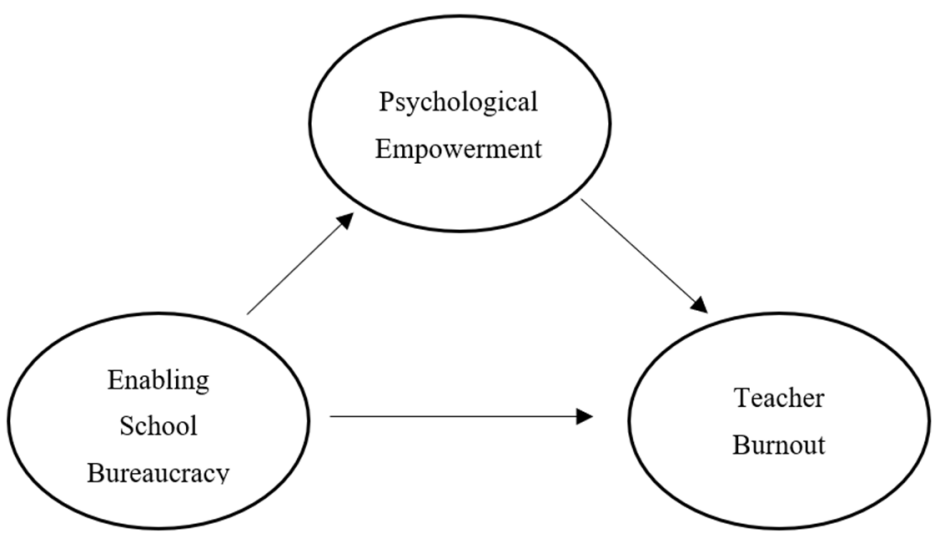

Figure 1. A theoretical framework of the relationships among enabling school bureaucracy, psychological empowerment, and teacher burnout.

\section{Materials and Methods}

\subsection{Participants}

The study surveyed primary and secondary schoolteachers who participated in professional development courses offered by a public university in Beijing from April to June 2020. First, the research team created an online questionnaire with Questionnaire Star, i.e., an online platform for questionnaire survey creation. Then, every teacher joining the professional development courses revised the link of the questionnaire and was invited to complete the online questionnaire after the courses.

After deleting 26 cases with missing data, the study ultimately included 322 participants. They came primarily from Shandong Province (31.4\%) and Beijing (20.9\%), followed by Guangdong Province (10.2\%), Henan Province (9.1\%), Hubei Province (7.8\%), Jiangxi Province (6.8\%), and Hebei Province (5.9\%), with the remaining 7.9\% coming from other provinces. Among the participants, the level of teaching experience was 9.58 years on average $(\mathrm{SD}=9.97)$, and their average age was 33.07 years old $(\mathrm{SD}=8.87)$. Regarding sex, 241 of the teachers were female, and 8 were male. In terms of educational background, all Chinese teachers had completed a college education, of which 94 teachers had a master's degree and 9 teachers had a doctoral degree. 


\subsection{Measurement}

\subsubsection{Enabling School Bureaucracy}

Enabling school bureaucracy was measured by the Enabling School Structure Scale (ESS) developed by Hoy and Sweetland [27]. The scale consisted of 12 items assessing the enabling characteristics of school bureaucracy. Each item was rated on a 5-point Likert-type scale ranging from 1 (strongly disagree) to 5 (strongly agree). Sample items included "Administrative rules in this school enable authentic communications between teachers and administrators" and "The administrative hierarchy of this school obstructs innovation" (score revised). In this study, the Cronbach's alpha for the ESS was 0.90.

\subsubsection{Psychological Empowerment}

The study applied Li et al.'s [61] psychological empowerment scale for Chinese society. The scale comprised 12 items measuring four dimensions of psychological empowerment, including 3 items for meaning, 3 items for competence, 3 items for self-determination, and 3 items for impact. Sample items for each dimension were "I find my work is meaningful" (meaning), "I am confident in my ability to do work well" (competence), "I enjoy autonomy to decide how to do my work" (self-determination), and "In my work, I have a great impact on what happens" (impact). Each item was rated on a 5-point Likert-type scale ranging from 1 (totally disagree) to 5 (totally agree). In this study, the Cronbach's alphas for meaning, competence, self-determination, and impact were $0.89,0.95,0.94$, and 0.94 , respectively.

\subsubsection{Teacher Burnout}

Li and Wang [62] translated the Maslach Burnout Inventory-Educators' Survey (MBIES), which was developed by Maslach, Jackson and Leiter [8], and contextualized it into the Chinese context. The Chinese version of the MBI-ES has 15 items measuring three dimensions of teacher burnout, including 5 items for emotional exhaustion, 4 items for depersonalization, and 6 items for reduced personal accomplishment. Each item was rated on a 7-point Likert-type scale ranging from 1 (completely disagree) to 7 (completely agree). Sample items for each dimension included "I feel emotionally drained from my work" (emotional exhaustion), "I doubt the significance of my work" (depersonalization), and "I have accomplished many worthwhile things in this job" (score revised) (reduced personal accomplishment). The Cronbach's alpha for emotional exhaustion, depersonalization, and reduced personal accomplishment were $0.95,0.93$, and 0.93 , respectively.

\subsection{Data Analysis}

All data analysis in this study was performed using SPSS 24.0 software. First, SPSS 24.0 was used to analyze the correlation of the data. Second, the researchers applied the SPSS 24.0 macro PROCESS 3.3 plug-in program compiled by Hayes [63], with enabling school bureaucracy as the independent variable, teacher burnout as the dependent variable, and psychological empowerment as the mediation variable, to test the mediation effect of psychological empowerment between enabling school bureaucracy and teacher burnout after controlling for sex and age. PROCESS 3.3 automatically generated three regression models: total effect value, direct effect value, and indirect effect value. When the upper and lower limits of the indirect effect value did not include 0 , psychological empowerment had a mediation effect. Finally, Hayes' [63] bootstrap technique (the number of repetitions was set to 5000) was used to investigate the significance of the mediation effect.

\section{Results}

\subsection{Correlation Analysis}

Table 1 shows the correlations among enabling school bureaucracy, psychological empowerment, and teacher burnout. The results suggested that teacher burnout was significantly and negatively correlated with enabling school bureaucracy $(r=-0.48, p<0.01)$ and psychological empowerment $(r=-0.53, p<0.01)$. In particular, the findings showed 
that three dimensions of teacher burnout were negatively correlated with enabling school bureaucracy and all dimensions of psychological empowerment. According to Table 1, moreover, enabling school bureaucracy was significantly and positively correlated with psychological empowerment $(r=0.39, p<0.01)$. Therefore, H1 and H2 were supported.

Table 1. Relationships among Enabling School Bureaucracy, Teacher Burnout, and Psychological Empowerment.

\begin{tabular}{|c|c|c|c|c|c|c|c|c|c|c|c|c|}
\hline & $\mathrm{S}$ & MD & 1 & 2 & 3 & 4 & 5 & 6 & 7 & 8 & 9 & 10 \\
\hline 1. Enabling structure & 3.30 & 0.82 & 1 & & & & & & & & & \\
\hline 2. Teacher burnout & 3.48 & 1.12 & $-0.48^{* *}$ & 1 & & & & & & & & \\
\hline 3.Emotional exhaustion & 4.30 & 1.63 & $-0.39^{* *}$ & $0.85^{* *}$ & 1 & & & & & & & \\
\hline 4. Depersonalization & 3.81 & 1.69 & $-0.44^{* *}$ & $0.88^{* *}$ & $0.80 * *$ & 1 & & & & & & \\
\hline 5.Lack of accomplishment & 2.58 & 1.16 & $-0.28 * *$ & $0.56^{* *}$ & 0.11 & $0.22 * *$ & 1 & & & & & \\
\hline 6.Psychological empowerment & 3.89 & 0.84 & 0.39 ** & -0.53 ** & $-0.28^{* *}$ & -0.34 ** & $-0.63^{* *}$ & 1 & & & & \\
\hline 7. Meaning & 4.04 & 0.89 & $0.38 * *$ & $-0.54 * *$ & $-0.29 * *$ & $-0.38^{* *}$ & $-0.60^{* *}$ & $0.88^{* *}$ & 1 & & & \\
\hline 8. Competence & 4.11 & 0.89 & 0.24 ** & $-0.49^{* *}$ & $-0.21 * *$ & -0.30 ** & -0.65 ** & 0.85 ** & $0.78^{* *}$ & 1 & & \\
\hline 9.Self-determination & 3.77 & 1.02 & 0.38 ** & $-0.46^{* *}$ & $-0.26^{* *}$ & -0.28 ** & $-0.53^{* *}$ & 0.91 ** & $0.69^{* *}$ & $0.65 * *$ & 1 & \\
\hline 10. Impact & 3.64 & 1.03 & $0.38^{* *}$ & $-0.42^{* *}$ & -0.23 ** & $-0.25^{* *}$ & $-0.49^{* *}$ & $0.89 * *$ & $0.66^{* *}$ & 0.62 ** & $0.83^{* *}$ & 1 \\
\hline
\end{tabular}

\subsection{Mediation Analysis}

By applying Hayes' [63] bootstrapping technique, which was also utilized to obtain confidence intervals (CIs) using SPSS PROCESS v.35 by employing Model 4, a mediation model was formed from three linear regression equations: teacher burnout and enabling school bureaucracy; psychological empowerment and enabling school bureaucracy; and teacher burnout, enabling school bureaucracy, and psychological empowerment. As Table 2 shows, enabling school bureaucracy could negatively predict teacher burnout (Coef. $=-0.60, S E=0.07, T=-8.68, p<0.001$ ) but positively predict psychological empowerment (Coef. $=0.38, S E=0.06, T=0.96, p<0.001)$. When psychological empowerment was included, the effect of enabling school bureaucracy on teacher burnout became nonsignificant. These findings indicated that psychological empowerment played a mediating role in the relationship between enabling school bureaucracy and teacher burnout.

According to Table 3, the upper and lower bounds of the bootstrap 95\% CIs for the effect of enabling school bureaucracy on teacher burnout and psychological empowerment did not contain zero, indicating that enabling school bureaucracy indirectly predicted teacher burnout through psychological empowerment (see Figure 2). The direct effect and the mediation effect accounted for $67.22 \%$ and $32.77 \%$ of the total effect, respectively. According to these analyses, $\mathrm{H} 3$ could be supported.

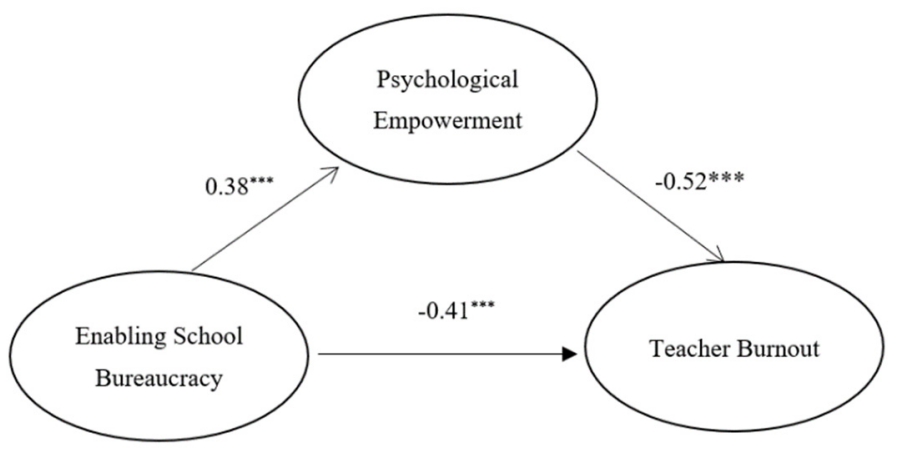

Note: ${ }^{* * *} p<.001$

Figure 2. Effects of Enabling School Bureaucracy on Teacher Burnout through Psychological Empowerment.

To further explore the mediation effects of each dimension of psychological empowerment, a parallel mediation analysis was computed. According to the results, the upper and lower limits of the bootstrap 95\% CIs for meaning and competence did not contain zero, and the mediation effects of these two factors were significant (see Table 4), indicating 
that enabling school bureaucracy could indirectly predict teacher burnout via meaning and competence. However, the upper and lower limits of the bootstrap 95\% CI for selfdetermination and impact did both contain zero (see Table 4), implying that their mediation effect was nonsignificant.

Table 2. Mediation Model Test for Psychological Empowerment.

\begin{tabular}{|c|c|c|c|c|c|c|c|}
\hline $\begin{array}{l}\text { Outcome } \\
\text { Variables }\end{array}$ & $\begin{array}{l}\text { Independent } \\
\text { Variables }\end{array}$ & Coef. & $S E$ & $T$ & $95 \% C I$ & $R 2$ & $F$ \\
\hline \multicolumn{8}{|c|}{ Teacher Burnout } \\
\hline & Constant & $5.37^{* * *}$ & 0.69 & 7.74 & {$[4.00,6.37]$} & \multirow{5}{*}{0.25} & \multirow{5}{*}{$25.41^{* * *}$} \\
\hline & Sex & -0.08 & 0.13 & -0.64 & {$[-0.34,0.17]$} & & \\
\hline & Age & 0.02 & 0.02 & 0.68 & {$[-0.03,0.06]$} & & \\
\hline & Teaching age & -0.03 & 0.02 & -1.38 & {$[-0.07,0.01]$} & & \\
\hline & $\begin{array}{c}\text { Enabling school } \\
\text { bureaucracy }\end{array}$ & $-0.60^{* * *}$ & 0.07 & -8.68 & {$[-0.74,-0.47]$} & & \\
\hline \multirow{2}{*}{\multicolumn{8}{|c|}{$\begin{array}{l}\text { Psychological } \\
\text { Empowerment }\end{array}$}} \\
\hline & & & & & & & \\
\hline & $\begin{array}{l}\text { Constant } \\
\text { Sex }\end{array}$ & $\begin{array}{l}2.76 \\
-0.12\end{array}$ & $\begin{array}{l}0.55 \\
0.10\end{array}$ & $\begin{array}{c}5.03 \\
-1.18\end{array}$ & $\begin{array}{c}{[1.68,3.84]} \\
{[-0.32,0.08]}\end{array}$ & \multirow{4}{*}{0.17} & \multirow{4}{*}{$15.53^{* * *}$} \\
\hline & Age & 0.00 & 0.02 & 0.02 & {$[-0.03,0.03]$} & & \\
\hline & Teaching age & 0.01 & 0.02 & 0.54 & {$[-0.02,0.04]$} & & \\
\hline & $\begin{array}{c}\text { Enabling school } \\
\text { bureaucracy }\end{array}$ & $0.38^{* * *}$ & 0.06 & 6.96 & {$[0.28,0.49]$} & & \\
\hline \multicolumn{8}{|c|}{ Teacher Burnout } \\
\hline & Constant & $6.79 * * *$ & 0.66 & 10.31 & {$[5.50,8.09]$} & \multirow{6}{*}{0.37} & \multirow{6}{*}{$36.82 * * *$} \\
\hline & Sex & -0.15 & 0.12 & -1.23 & {$[-0.38,0.09]$} & & \\
\hline & Age & 0.02 & 0.02 & 0.75 & {$[-0.02,0.06]$} & & \\
\hline & Teaching age & -0.02 & 0.02 & -1.26 & {$[-0.06,0.01]$} & & \\
\hline & $\begin{array}{c}\text { Enabling school } \\
\text { bureaucracy }\end{array}$ & $-0.41^{* * *}$ & 0.07 & -5.94 & {$[-0.54,-0.27]$} & & \\
\hline & $\begin{array}{l}\text { Psychological } \\
\text { Empowerment }\end{array}$ & $-0.52 * * *$ & 0.07 & -7.90 & {$[-0.65,0.39]$} & & \\
\hline
\end{tabular}

$* * * p<0.001$.

Table 3. Total, Direct, and Mediation Effects of Psychological Empowerment.

\begin{tabular}{lccccc}
\hline & Effect & $\begin{array}{c}\text { Bootstrap } \\
\text { Standard } \\
\text { Error }\end{array}$ & $\begin{array}{c}\text { Bootstrap } \\
\text { LLCI }\end{array}$ & $\begin{array}{c}\text { Bootstrap } \\
\text { ULCI }\end{array}$ & $\begin{array}{c}\text { Relative } \\
\text { Effect Size }\end{array}$ \\
\hline Total Effects & -0.60 & 0.09 & -0.78 & -0.44 & \\
$\begin{array}{l}\text { Direct Effects } \\
\text { Mediation Effects of }\end{array}$ & -0.41 & 0.09 & -0.58 & -0.23 & $67.22 \%$ \\
$\begin{array}{l}\text { Psychological } \\
\text { Empowerment }\end{array}$ & -0.20 & 0.04 & -0.29 & -0.12 & $32.77 \%$ \\
\hline $\begin{array}{l}\text { Note: Bootstrapping was set at 5000 samples. } \\
\text { Nots }\end{array}$ & & & & \\
\hline
\end{tabular}

Table 4. Parallel Mediation Breakdown of Dimensions of Psychological Empowerment.

\begin{tabular}{lccccc}
\hline & Effect & $\begin{array}{c}\text { Standard } \\
\text { Error }\end{array}$ & $\begin{array}{c}\text { Bootstrap } \\
\text { LLCI }\end{array}$ & $\begin{array}{c}\text { Bootstrap } \\
\text { ULCI }\end{array}$ & Effect Ratio \\
\hline Total Mediation Effect & -0.18 & 0.05 & -0.28 & -0.08 & $29.24 \%$ \\
Meaning & -0.11 & 0.04 & -0.19 & -0.03 & $18.04 \%$ \\
Competence & -0.04 & 0.02 & -0.09 & -0.01 & $7.34 \%$ \\
Self-determination & -0.07 & 0.05 & -0.18 & 0.02 & $11.64 \%$ \\
Impact & 0.05 & 0.05 & -0.05 & 0.15 & $7.77 \%$ \\
\hline
\end{tabular}

Note: Bootstrapping was set at 5000 samples.

\section{Discussion}

In the last two decades, teachers have been widely reported to be at risk of burnout across the globe $[10,13]$. Since burnout may affect teacher effectiveness and wellbeing, 
education researchers have investigated the antecedents of teacher burnout to provide recommendations to alleviate it $[1,16,18]$. Different from most of the existing psychological research that focuses only on the impacts of psychological factors on teacher burnout, the present study attempts to examine how teacher burnout is influenced by both psychological and structural factors. Based on empowerment theory [29-31,41,42], the study examines the relationships among enabling school bureaucracy, psychological empowerment, and teacher burnout. According to the findings, enabling school bureaucracy and psychological empowerment may significantly alleviate teacher burnout. The findings imply that if teachers are structurally or psychologically empowered, they may have greater power to control their work and identify the meanings of the work to themselves [64], or a stronger sense of meaning, competence, self-determination, and impact [36], leading to a lower degree of burnout $[60,65]$.

Moreover, as empowerment theory suggests $[39,60]$, the findings show that psychological empowerment may mediate the effects of enabling school bureaucracy as a form of structural empowerment. In other words, enabling school bureaucracy may not only alleviate teacher burnout by structurally empowering teachers but also enhance teachers' cognitive state of mind about their capability to influence their work and social environment. However, this does not mean that all dimensions of psychological empowerment are mediators between enabling school bureaucracy and teacher burnout. According to the parallel mediation analysis, only meaning and competence have mediation effects but not self-determination and impact. The findings can be explained as follows: First, enabling school bureaucracy is still a bureaucratic structure valuing formalization and centralization, even though it tends to emphasize fixable guidelines encouraging teachers to exercise their professional judgment in doing their work and to facilitate collaboration and cooperation between school administration and teachers [27]. In other words, teachers may not have the ultimate power to determine what and how to do their work because they are still subject to certain rules, regulations, and bureaucratic authority. Thus, although enabling school bureaucracy may structurally empower them to work, it may not necessarily reduce teacher burnout by enhancing their sense of self-determination. Second, for teachers, the major outcomes of their work are students' educational attainment. Nevertheless, in addition to teachers, there are many factors, such as students' intelligence and family background, affecting students' educational attainment, and many of these factors are out of the teachers' control [66]. Therefore, even though teachers are able to take care of students' overall development through school bureaucracy, they may not necessarily attribute the successful outcomes to their own efforts. Thus, the sense of impact may not significantly mediate the relationship between enabling school bureaucracy and teacher burnout.

Accordingly, the present study generally supports empowerment theory, but the findings extend the understanding of the relationships between enabling school bureaucracy and structural empowerment, psychological empowerment, and teacher burnout. The study implies that different dimensions of psychological empowerment may have different mediation effects between structural empowerment and teacher burnout. Thus, further studies should differentiate each dimension of psychological empowerment to provide a more comprehensive analysis of the relationships among psychological empowerment, structural empowerment, and teacher burnout.

\section{Conclusions}

According to the study, teacher burnout may be alleviated by enabling school bureaucracy and psychological empowerment. In particular, the study shows that the relationship between enabling school bureaucracy and teacher burnout may be mediated by psychological empowerment, especially its dimensions of meaning and competence. The research findings have the following implications for school administration: First, it is recommended that school administrators develop an enabling school bureaucracy that aims to share power and authority with teachers and facilitate teachers to exercise their professional judgment in teaching. This is because enabling bureaucracy may directly alleviate teacher burnout 
and indirectly reduce the level of teacher burnout by enhancing their sense of meaning and competence. To achieve that, they should involve teachers in the school decision-making process, emphasize professional accountability instead of managerial accountability, and develop flexible rules and regulations to support teachers' innovation for problem-solving. Second, they should also psychologically empower teachers by providing more channels for teachers to learn the purposes and values of the assigned instructional and noninstructional duties, giving them constructive feedback for improving teaching, creating opportunities for students to show appreciation for their teaching efforts, and delegating greater power for them to do their work at the classroom level, because these practices may help develop teachers' sense of meaning, competence, self-determination, and impact [67].

One of the limitations of the study is sampling. The study samples only teachers from professional development courses offered by a university in Beijing, China. To some extent, teachers who take part in professional development courses may have higher motivation for self-improvement. In some of the courses, the participants were competent teachers officially recognized by their schools, districts, cities, and even provinces. In other words, the findings may not represent the whole teacher population in China. Thus, further studies should employ random sampling strategies to select teachers across China to check whether the findings of the present study are replicated. Second, the study only replies on teachers' self-report on the syndrome of burnout, psychological empowerment, and enabling bureaucracy. Thus, the analysis may not accurately reflect their level of burnout. Thus, further study should also adopt objective measures such as expert analysis and observation in addition to self-report for triangulation leading to more robust findings. Moreover, the present study has a cross-sectional design, sothe causal relationships among enabling school bureaucracy, psychological empowerment, and teacher burnout may not be well established. To supplement this limitation, it is suggested that researchers conduct longitudinal studies to address this issue. Finally, there may be cultural differences associated with structural empowerment, psychological empowerment, and teacher burnout. Since the present study focuses only on the Chinese context, the findings may not be generalizable to other cultural contexts. Therefore, other researchers may consider conducting comparative studies to test cultural differences.

Author Contributions: Conceptualization, K.K.T.; methodology, K.K.T.; formal analysis, G.W. and H.B.; investigation, K.K.T.; resources, K.K.T.; writing-original draft preparation, K.K.T. and G.W.; writing-review and editing, K.K.T., G.W. and H.B.; supervision, K.K.T.; project administration, K.K.T.; funding acquisition, K.K.T. All authors have read and agreed to the published version of the manuscript.

Funding: This research was funded by the Humanities and Social Science Research Scheme of the Ministry of Education of China, grant number 20YJC880002.

Institutional Review Board Statement: The study was conducted in accordance with the Declaration of Helsinki, and approved by the Ethics Committee of the Faculty of Education Beijing Normal University (protocol code BNU202109100022, approved by 28 September 2021).

Informed Consent Statement: Informed consent was obtained from all subjects involved in the study.

Data Availability Statement: The data presented in this study are available on request from the corresponding author. The data are not publicly available due to confidentiality and research ethics.

Conflicts of Interest: The authors declare no conflict of interest. 


\section{References}

1. Saloviita, T.; Pakarinen, E. Teacher burnout explained: Teacher-, student-, and organisation-level variables. Teach. Teach. Educ. 2021, 97, 103221. [CrossRef]

2. Chang, M.L. Toward a theoretical model to understand teacher emotions and teacher burnout in the context of student misbehavior: Appraisal, regulation and coping. Motiv. Emot. 2013, 37, 799-817. [CrossRef]

3. Prakke, B.; van Peet, A.; van der Wolf, K. Challenging parents, teacher occupational stress and health in Dutch primary schools. Int. J. About Parents Educ. 2007, 1, 36-44.

4. Rowan, B. Comparing teachers' work with work in other occupations: Notes on the professional status of teaching. Educ. Res. 1994, 23, 4-17. [CrossRef]

5. Brante, C. Multitasking and synchronous work: Complexities in teacher work. Teach. Teach. Educ. 2009, 25, 430-436. [CrossRef]

6. Lee, S.; Tsang, A.; Kwok, K. Stress and mental disorders in a representative sample of teachers during education reform in Hong Kong. J. Psychol. Chin. Soc. 2007, 8, 159-178.

7. Squillaci, M. Are teachers more affected by burnout than physicians, nurses and other professionals? A systematic review of the literature. In Advances in Human Factors and Ergonomics in Healthcare and Medical Devices; Lightner, N., Kalra, J., Eds.; Springer: New York, NY, USA, 2019; pp. 147-155.

8. Maslach, C.; Jackson, S.E.; Leiter, M.P. The Maslach Burnout Inventory Manual, 4th ed.; CPP, Inc.: Sunnyvale, CA, USA, 1996.

9. Bianchi, R.; Schonfeld, I.S.; Mayor, E.; Laurent, E. Burnout-depression overlap: A study of New Zealand schoolteachers. N. Z. J. Psychol. 2016, 45, 4-11.

10. García-Carmona, M.; Marín, M.D.; Aguayo, R. Burnout syndrome in secondary school teachers: A systematic review and meta-analysis. Soc. Psychol. Educ. 2019, 22, 189-208. [CrossRef]

11. Koutsimani, P.; Montgomery, A.; Georganta, K. The Relationship between burnout, depression, and anxiety: A systematic review and meta-analysis. Front. Psychol. 2019, 10, 284. [CrossRef]

12. Akdemir, Ö.A. The effect of teacher burnout on organizational commitment in Turkish context. J. Educ. Train. Stud. 2019, 7, 171-179. [CrossRef]

13. Iancu, A.E.; Rusu, A.; Măroiu, C.; Păcurar, R.; Maricuțoiu, L.P. The effectiveness of interventions aimed at reducing teacher burnout: A meta-analysis. Educ. Psychol. Rev. 2018, 30, 373-396. [CrossRef]

14. Kokkinos, C.M. Job stressors, personality and burnout in primary school teachers. Br. J. Educ. Psychol. 2007, 77, 229-243. [CrossRef]

15. Skaalvik, E.M.; Skaalvik, S. Teacher self-efficacy and teacher burnout: A study of relations. Teach. Teach. Educ. 2010, 26, 1059-1069. [CrossRef]

16. Chan, D.W.; Hui, E.K.P. Burnout and coping among Chinese secondary school teachers in Hong Kong. Br. J. Educ. Psychol. 1995, 65, 15-25. [CrossRef]

17. Chan, D.W. Emotional intelligence and components of burnout among Chinese secondary school teachers in Hong Kong. Teach. Teach. Educ. 2006, 22, 1042-1054. [CrossRef]

18. Pietarinen, J.; Pyhältö, K.; Soini, T.; Salmela-Aro, K. Reducing teacher burnout: A socio-contextual approach. Teach. Teach. Educ. 2013, 35, 62-72. [CrossRef]

19. Leiter, M.P.; Maslach, C. Preventing Burnout and Building Engagement. A Complete Program for Organizational Renewal; Jossey-Bass: San Francisco, CA, USA, 2000.

20. Betoret, F.D. Self-efficacy, school resources, job stressors and burnout among Spanish primary and secondary school teachers: A structural equation approach. Educ. Psychol. 2009, 29, 45-68. [CrossRef]

21. Friedman, I.A. High- and low-burnout schools: School culture aspects of teacher burnout. J. Educ. Res. 1991, 84, 325-333. [CrossRef]

22. Moliner, C.; Martinez-Tur, V.; Peiro, J.M.; Ramos, J.; Cropanzano, R. Relationships between organizational justice and burnout at the work-unit level. Int. J. Stress Manag. 2005, 12, 99-116. [CrossRef]

23. Skaalvik, E.M.; Skaalvik, S. Dimensions of teacher burnout: Relations with potential stressors at school. Soc. Psychol. Educ. 2017, 20, 775-790. [CrossRef]

24. Schaufeli, W.B.; Bakker, A.B. Job demands, job resources, and thehir relationship with burnout and engagment: A multi-sample study. J. Organ. Behav. 2004, 25, 293-315. [CrossRef]

25. Schwab, R.L. Teacher burnout: Moving beyond "psychobabble". Theory Pract. 1983, 22, 21-26. [CrossRef]

26. Adler, P.S.; Borys, B. Two types of bureaucracy: Enabling and coerecive. Adm. Sci. Q. 1996, 41, 61-89. [CrossRef]

27. Hoy, W.K.; Sweetland, S.R. Besigning better schools: The meaning and measure of enabling school structures. Educ. Adm. Q. 2001, 37, 296-321. [CrossRef]

28. Sadan, E. Empowerment and Community Planning: Theory and Practice of People-Focused Social Solutions; Hakibbutz Hameuchad: Tel Aviv, Israel, 1997.

29. Zimmerman, M.A.; Israel, B.A.; Schulz, A.; Checkoway, B. Futher explorations in empowerment theory: An empirical analysis of psychological empowerment. Am. J. Community Psychol. 1992, 20, 707-727. [CrossRef]

30. Rappaport, J. Studies in empowerment: Introduction to the issue. Prev. Hum. Serv. 1984, 3, 1-7. [CrossRef]

31. Joseph, R. The theory of empowerment: A critical analysis with the theory evaluation scale. J. Hum. Behav. Soc. Environ. 2020, 30, 138-157. [CrossRef] 
32. Eljaaidi, N. Structural and psychological empowerment: A literature review, theory clarifications and strategy building. J. Econ. Political Sci. 2016, 7, 446-479.

33. Kanter, R.M. Men and Women of the Corporation, 2nd ed.; Basic Books: New York, NY, USA, 2003.

34. Mills, P.K.; Ungson, C.R. Reassessing the limits of structural empowerment: Organizational constitution and trust as controls. Acad. Manag. Rev. 2003, 28, 143-153. [CrossRef]

35. Conger, J.A.; Kanungo, R.N. The empowerment process: Integrating theory and practice. Acad. Manag. Rev. 1988, 13, 471-482. [CrossRef]

36. Spreitzer, G.M. Psychological empowerment in the workplace: Dimensions, measurement, and validation. Acad. Manag. Perspect. 1995, 38, 1442-1465.

37. Taebi, M.; Simbar, M.; Abdolahian, S. Psychological empowerment strategies in infertile women: A systemic review. J. Educ. Health Promot. 2018, 7, 68. [CrossRef]

38. Laschinger, S.H.K.; Finegan, J.; Shamian, J.; Wilk, P. Impact of strutural and psychological empowerment on job strain in nursing work settings. J. Nurs. Adm. 2001, 31, 260-272. [CrossRef]

39. Paryadharshany, A.J.; Sujatha, S. Does structural empowerment impact on job satisfaction via psychological empowerment? A mediation analysis. Glob. Manag. Rev. 2015, 10, 23-42.

40. Zhang, X.; Ye, H.; Li, Y. Correlates of structural empowerment, psychological empowerment and emotional exhaustion among registered nurses: A meta-analysis. Appl. Nurs. Res. 2018, 42, 9-16. [CrossRef]

41. Weidenstedt, L. A Sociology of Empowerment: The Relevance of Communicative Contexts for Workplace Change; Stockholm University: Stockholm, Sweden, 2017.

42. Spreitzer, G.M. Social structural characteristics of psychological empowerment. Acad. Manag. J. 1996, 39, 483-504. [CrossRef]

43. Ingersoll, R.M. The anomaly of educational organizations and the study of organizational control. In The Social Organization of Schooling; Hedges, L.V., Schneider, B., Eds.; Russell Sage Foundation: New York, NY, USA, 2005; pp. 91-110.

44. Lee, T.T.-L.; Kwan, P.; Li, B.Y.M. Neoliberal challenges in context: A case of Hong Kong. Int. J. Educ. Manag. 2020, 34, 641-652. [CrossRef]

45. Merton, R.K. Social Theory and Social Structure; Free Press: New York, NY, USA, 1968.

46. Anderson, B.D. School bureaucratization and alienation from high school. Sociol. Educ. 1973, 46, 315-334. [CrossRef]

47. Dworkin, A.G. Teacher burnout and teacher resilience: Assessing the impact of the school accountability movement. In International Handbook of Research on Teachers and Teaching; Saha, L.J., Dworkin, A.G., Eds.; Springer: New York, NY, USA, 2009; pp. 491-509.

48. Beard, K.S.; Hoy, W.K.; Hoy, A.W. Academic optimism of individual teachers: Confirming a new construct. Teach. Teach. Educ. 2010, 26, 1136-1144. [CrossRef]

49. Tsang, K.K.; Liu, D. Teacher demoralization, disempowerment and school administration. Qual. Res. Educ. 2016, 5, 200-225. [CrossRef]

50. Tang, T.O.; Yeung, A.S. Hong Kong teachers' sources of stress, burnout, and job satisfaction. In Proceedings of the International Conference on Teacher Education, Hong Kong, China, 22-24 February 1999.

51. Santoro, D.A. Teacher Demoralization and Teacher Burnout: Why the Distinction Matters. Available online: http://www. ajeforum.com/teacher-demoralization-and-teacher-burnout-why-the-distinction-matters / (accessed on 9 May 2015).

52. Powell, W.E. The Relationship between Feelings of Alienation and Burnout in Social Work. Fam. Soc.: J. Contemp. Soc. Serv. 1994, 75, 229-235. [CrossRef]

53. Li, Y.; Wei, F.; Ren, S.; Di, Y. Locus of control, psychological empowerment and intrinsic motivation relation to performance. J. Manag. Psychol. 2015, 30, 422-438. [CrossRef]

54. Boudrias, J.-S.; Morin, A.J.S.; Brodeur, M.-M. Role of psychological empowerment in the reduction of burnout in Canadian healthcare workers. Nurses Health Sci. 2012, 14, 8-17. [CrossRef]

55. Ghaniyoun, A.; Shakeri, K.; Heidari, M. The association of psychological empowerment and job burnout in operational staff of Tehran emergency center. Indian J. Crit. Care Med. 2017, 21, 563-567. [CrossRef]

56. Zhu, X.L. An inquiry into the relatsionhip between primary school teacher burnout and psychological empowerment. Contemp. Educ. Sci. 2013, 24, 30-31. (In Chinese)

57. Tsang, K.K.; Du, Y.; Teng, Y. Transformational leadership, teacher burnout, and psychological empowerment: A mediation analysis. Soc. Behav. Personal. Int. J. 2022, 50, e11041. [CrossRef]

58. Maynard, M.T.; Gilson, L.L.; Mathieu, J.E. Empowerment-Fad or Fab? A multilevel review of the past two decades of research. J. Manag. 2012, 38, 1231-1281. [CrossRef]

59. Knol, J.; Linge, R.V. Innovative behaviour: The effect of strutural and psychological empowerment on nurses. J. Adv. Nurs. 2009, 65, 359-370. [CrossRef]

60. Meng, L.; Jin, Y.; Guo, J. Mediating and/or moderating roles of psychological empowerment. Appl. Nurs. Res. 2016, 30, 104-110. [CrossRef]

61. Li, C.; Tian, B.; Shi, K. Transformational leadership and employee work attitudes: The mediating effects of multidimensional psychological empowerment. Acta Psychol. Sin. 2006, 38, 297-307. (In Chinese)

62. Li, C.; Wang, H. Relationship between time management and job burnout of teachers. Chin. J. Clin. Psychol. 2009, 17, 107-109. (In Chinese) [CrossRef] 
63. Hayes, A.F. Introduction to Mediation, Moderation, and Conditional Process Analysis: A Regression-Based Approach; Guilford Press: New York, NY, USA, 2013.

64. Tsang, K.K. The structural causes of teacher burnout in Hong Kong. Chin. Educ. Soc. 2018, 51, 449-461. [CrossRef]

65. Pearson, L.C.; Moomaw, W. The relationship between teacher autonomy and stress, work satisfaction, empowerment, and professionalism. Educ. Res. Q. 2005, 29, 38-54.

66. Luster, T.; McAdoo, H. Family and child influences on educational attainment: A secondary analysis of the high/scope Perry Preschool data. Dev. Psychol. 1996, 32, 26-39. [CrossRef]

67. Tsang, K.K. Teachers' Work and Emotions: A Sociological Analysis; Routledge: London, UK, 2019. 